\title{
Study on the body shapes of old aged obese women for the activation of the silver clothing industry
}

\author{
Ok jin Seong and Sook jin $\mathrm{Kim}^{\dagger}$ \\ Lab. of Fashion Design, Sejong University \\ 실버 의류산업 활성화를 위한 노년 비만여성의 체형연구 \\ 성 옥 진 · 김 숙 진 ${ }^{+}$ \\ 세종대학교 패션디자인연구소
}

\begin{abstract}
This study analyzed the body-type characteristics of 340 old-aged obese women that had been on the rise as a part of efforts to activate the silver clothing industry. The subjects were in the age range of 60-79 and met some obesity requirements, including a Rohrer Index of 1.6 or higher, a BMI of 25 or higher, and a WHR of 0.85 or higher. Old-aged obese women showed increased thickness of the torso with age, which suggests that they revealed the characteristics of regardless of gender. In other words, they became bigger in the waist and abdomen, shorter in height, slimmer in the lower body, and thicker in the torso. There are three types of obesity: Type 1 is lower-body obesity with a higher degree of obesity in the abdomen than the upper body. Type 2 is abdominal obesity with a higher degree of obesity in the upper body than in the lower body. Type 3 is whole-body obesity with balanced obesity of the whole body. As for changes to the types of obesity according to age, those who are in their sixties usually fall into the categories of upper-body and whole-body obesity, and those who are in their seventies are much more concentrated in the categories of abdominal obesity and upper-body obesity with a decreased percentage of whole-body obesity. It is apparent that the percentage of abdominal and upper-body obesity rises with age due to fat accumulation in the abdomen.
\end{abstract}

Key word: old aged obese women(노년 비만여성), factor analysis(요인분석), BMI(체질량지수), silber clothing industry(실버 의류산업), obesity body type(비만체형)

\section{Introduction}

의료기술의 발달과 건강에 대한 관심 고조로 인 간의 평균수명은 연장되고, 노인인구는 갈수록 증가
하고 있다. Statistics Korea(2011)에 따르면 2010년 한국의 노령화지수는 67.7 로, 유소년인구(0 14세) 100 명당 65 세 이상 인구가 68 명이며, 2016년에 이 르면 노령화지수가 100.7 로 고령인구가 유소년인구

Received 10 June 2015, revised 23 July 2015, accepted 27 July 2015.

This work was supported by the National Research Foundation of Korea Grant funded by the Korean Government [NRF-2014S1A5B5A02015110].

This research is supported by Ministry of Culture, Sports and Tourism (MCST) and Korea Creative Content Agency (KOCCA) in the Human Resources Research \& Development Program 2015.

${ }^{+}$Corresponding author (ksjina@sejong.ac.kr) 
를 초과할 것으로 전망하고 있다. 또한 한국의 고령 화 진입속도는 미국, 프랑스 등 기타 선진국에 비해 매우 빠르게 진행되고 있고, 고령인구 비율이 $14 \%$ 에서 $20 \%$ 로 도달하는데 걸리는 시간이 8 년에 불과 할 정도여서, 고령사회를 대비한 정책이 필요한 시 점이다. 게다가 2007년 세계보건기구(WHO)가 발표 한 통계에 따르면 한국남성의 평균기대수명은 75세, 여성은 82세로 남녀 평균수명의 차이로 인해 80 세 이상의 고령인구에서는 여자노인의 인구비율이 더 욱더 높아진다고 하였다(Lee, 2009).

반면에 과체중이나 비만으로 인한 여러 가지 합 병증은 이러한 기대수명을 단축되는 요인으로 작용 하기도 한다. 우리나라 성인 비만율(BMI 25 이상) 은 2005 년 기준 남자 $35.2 \%$, 여자 $28.3 \%$ 로 꾸준한 증가 추세에 있으며, 연령별로 비만 유병율을 살펴보 면 남자는 40 대와 50 대, 여자는 50 대와 60 대에서 비 만율이 높은 것으로 나타났다(Korea Health Industry Development Institute, 2006). 특히 여성의 경우, 노 년기에 접어들면서 상반신이 굽거나 키가 작아지면 서 비만으로 변화되는 경우가 많다. 하지만, 노인 인 구의 많은 비중을 차지하고 있는 비만체형에 대해 서 연구자료가 매우 부족한 실정이며, 이에 대한 연 구가 절실히 필요하다.

과거 노년층은 노후를 자식에 의존하여 생활하였 지만, 최근에 노년층은 경제력을 바탕으로 여행이나 레저, 각종 취미활동, 평생교육 등 활발한 사회활동 을 하는 구매력 있는 집단으로 부상하여 의료, 건강 등 고령자를 위한 새로운 실버산업이 팽창하고 있다.

또한 노년여성의 사회활동의 폭이 커짐에 따라 의복에 대한 관심도 높아지게 되었고, 기성복이 일 반화되고 다양화되면서 의복선택의 폭은 넓어졌지 만, 의복착용 시 맞음새에 대해 불만족하는 사례들 도 늘고 있다. Lee and Joo(2005)의 선행연구에서는 재킷 착용의 불만족 부위로 옷길이, 소매길이, 어깨 너비, 가슴둘레 등을 제시하였고, 바지와 스커트의 경우 바지길이와 허리둘레가 수선비율이 가장 높은 것으로 조사되었다. 뿐만 아니라 연령이 높고 사이 즈가 클수록 수선 비율이 높았으며, 비만체형은 의복 구입 시 $78 \%$ 가 수선을 경험한다고 하였다(Lee, 2002). 이렇게 불만족 사례가 늘고 있는 것은 비만체형의 특성이 패턴에 반영되지 못해 발생한 문제점이라 생
각되며, 이와 같은 문제점을 해결하기 위해서는 정 확한 신체정보를 반영한 패턴설계가 이루어져야 하 며, 이를 통해 노년 비만여성의 기성복 착용 만족도 를 향상시킬 수 있을 것이라 생각된다.

그러나 비만체형 중에 특히 60대 이상 노년 비만 체형이나 패턴에 대한 학문적 연구는 미미한 실정 이며, 비만체형에 대한 연구는 주로 20 50대 위주로 진행되어, 정작 비만이 가장 증가하는 노년기에 이 르는 60 대 이후의 비만체형에 대한 연구는 거의 이 루어지지 않고 있다. 뿐만 아니라 패턴 연구에서도 복부 비만 여성을 위한 슬랙스 패턴개발 연구를 제 외하면 전무한 실정이다.

이에 본 연구는 실버 의류산업 활성화의 일환으 로 증가 추세에 있는 60 79세의 노년 비만여성을 대 상으로 하였으며, ‘제5차 한국인 인체치수조사' 자료

(Korean Agency for Technology and Standards, 2004) 를 토대로 하여 비만집단의 신체적 특징을 분석하 고, 체형 유형화를 통해 비만여성의 체형별 특징을 파악하여, 체형 특성이 반영된 패턴 제작이 가능하 도록 의복설계의 기초자료를 제공하는 데에 목적이 있다. 이는 신체적 합성과 착용 만족도가 높은 기성복 개발에 도움이 되는 자료로 활용될 수 있을 것이다.

\section{Methods}

\section{Criteria to diagnose obesity}

현대사회에서는 노인의 비만 유병율이 지속적으 로 증가되고 있으며, 활동량 감소에 따른 복부비만 이 노인 비만의 특징으로 보고되고 있다(Kim, 2010). 의류학적인 측면에서 최근 연구들은 일반 성인을 기준으로 Rohrer 지수, Vervaeck 지수, 체질량지수 (body mass index: BMI), 허리둘레 기준, 가슴둘레 기준, 복부지방율(Waist-Hip Ratio: WHR) 즉 허리엉덩이 둘레비와 같은 비만 진단기준이 사용되어 왔다(Table 1).

이를 살펴보면 신체 비만도를 나타내는 Rohrer 지 수는 성인을 기준으로 일반적으로 1.5 이상을 비만 으로 분류하나, 연구자에 따라 차이를 나타내는데, 연령이 높아질수록 증가하기 때문에 1.6 이상을 비 만으로(Choi \& Lee, 1995) 보기도 한다. 체질량지수 $(\mathrm{BMI})$ 를 기준으로 할 때 성인은 25 이상을 비만으 
〈Table 1〉 Criteria to diagnose obesity \& previous studies on obesity diagnosis

\begin{tabular}{|c|c|c|c|}
\hline Division & Calculation & Criteria & Previous studies \\
\hline \multirow{2}{*}{ Rohrer } & \multirow{2}{*}{ Weight $(\mathrm{kg}) /$ Stature $(\mathrm{cm})^{3} \times 10^{5}$} & 1.5 over & Seok \& Kim(2003), Ha(2002) \\
\hline & & 1.6 over & Choi \& Lee(1995), Lee(1996) \\
\hline Vervaeck & $\begin{array}{l}\text { Weight }(\mathrm{kg})+\text { Bust. } \mathrm{C}(\mathrm{cm}) / \\
\quad \text { Stature }(\mathrm{cm})) \times 10^{2}\end{array}$ & 92.3 over & Choi \& Lee(1995) \\
\hline BMI & Weight $(\mathrm{kg}) /$ Stature $(\mathrm{m})^{2}$ & 25 over & $\begin{array}{l}\text { Yoon \& Choi(2009), Korean Society for the Study of Obesity } \\
\text { (2012), Korean Agency for Technology and Standards (2006), } \\
\text { Minstry of Health \& Welfare(2009), Seong \& Ha(2012), } \\
\text { Choi, Han, \& Nam(2009), Kim \& Lee(2008) }\end{array}$ \\
\hline Waist. C & $\begin{array}{l}\text { Waist }>85 \mathrm{~cm}(\text { female }) \\
\text { Waist }>90 \mathrm{~cm}(\text { male })\end{array}$ & $\begin{array}{l}\text { Female: } 85 \mathrm{~cm} \text { over } \\
\text { Male: } 90 \mathrm{~cm} \text { over }\end{array}$ & Korean Society for the Study of Obesity(2012) \\
\hline Bust. C & Bust. $\mathrm{C}>90 \mathrm{~cm}($ female $)$ & Female: $90 \mathrm{~cm}$ over & Ha(2002), Choi \& Lee(1995), Lee(1996) \\
\hline WHR & $\begin{array}{c}\text { Waist. C - Hip. C > } \\
0.85 \text { (female), Waist. C - } \\
\text { Hip. C }>1.00(\text { male })\end{array}$ & $\begin{array}{l}\text { Female: } 0.85 \text { over } \\
\text { Male: } 1.00 \text { over }\end{array}$ & $\begin{array}{l}\text { Korean Agency for Technology and Standards(2006), Kim } \\
\text { \& Choi(2006) }\end{array}$ \\
\hline
\end{tabular}

로 정의하기도 하고, Korean Society for the Study of Obesity(2012)에서는 노인 복부비만의 기준을 남성 $90 \mathrm{~cm}$ 이상, 여성 $85 \mathrm{~cm}$ 이상의 허리둘레로 규정하기 도 한다. 복부지방율(Waist-Hip Ratio: WHR)은 간단 하면서 비교적 정확한 복부비만 정도를 알 수 있는 지표로 여성은 0.85 , 남성은 1.00 이상을 기준으로 비 만을 표시하기도 한다. 이에 본 연구는 여러 가지 비 만진단 기준 중에 최근에 많이 사용되고 있는 비만 기준을 참고로 하여 연구대상을 선정하고자 한다.

\section{Subjects}

노년을 구분하는 기준은 연구자에 따라 다르지만, 본 연구는 선행 연구(Kim \& Choi, 2006; Lee, Kim, $\& \mathrm{Kim}, 2006$ )를 참고하여 '제5차 한국인 인체치수조 사' 자료(Korean Agency for Technology and Standards, 2004) 중 60 79세의 노년 여성을 대상으로 Rohrer 지수 1.6 이상, 체질량지수(BMI) 25 이상, 복부지방 율(WHR) 0.85 이상을 만족시키는 비만여성을 연구 집단으로 선정하였다. 최근에 발표된 '제6차 한국인 인체치수조사' 자료의 경우, 69 세까지를 피험자로 선 정한 반면에 '제 5 차 한국인 인체치수조사 자료'는 90 세까지를 피험자로 선택하고 있어, 본 연구에서는 연령을 확대하여 연구하고자 제 5 차의 자료를 선택 하였다. 또한 선정된 피험자는 측정항목 중 결항이 있는 피험자를 제외한 658 명의 자료를 사용하였다.
〈Table 2〉는 각각의 비만지수에 따른 비만판정기 준 및 연구대상의 인원수를 종합하여 분석한 것이 다. 이를 살펴보면 체질량지수(BMI) 25 이상에 속하 는 비만 인원수는 355 명인데 비하여, Rohrer 지수 1.6 이상에 속하는 인원수는 440 명, 복부지방율(WHR) 0.85 이상을 나타내는 비만인원수는 589명으로 나타 났으며, 세 가지 비만지수(BMI, Rohrer, WHR)를 모 두 만족시키는 인원은 340 명으로 이를 연구대상으 로 하였다.

\section{Measurement items}

본 연구의 신체특징 분석에 사용된 자료는 '제 5 차 한국인 인체치수조사'(Korean Agency for Technology and Standards, 2004)에서 측정한 직접측정치 항목 중 높이 6항목, 둘레 11항목, 너비 5항목, 두께 6항목, 길이 8항목, 몸무게 등의 총 37 항목으로 여성의류 제 작 시 꼭 필요한 인체측정 항목으로 선정하였다.

\section{Data analysis}

\section{1) Body measurement analysis}

노년 비만여성의 60 대와 70 대의 신체적 차이점 을 독립표본 $T$ 검정을 통해 비교 분석하고, 일반체 형과 비만체형의 신체적 차이점을 비교하여 패턴제 작 시 고려되어야할 위치를 연구한다. 
〈Table 2〉 The obesity diagnosis criteria and number of subjects

\begin{tabular}{|c|c|c|c|c|c|}
\hline Index & \multicolumn{2}{|c|}{ Diagnose criteria } & $\begin{array}{c}\text { Normal body types } \\
n=318(\%)\end{array}$ & $\begin{array}{c}\text { Obese body types } \\
n=340(\%)\end{array}$ & $\begin{array}{l}\text { Total } \\
(\%)\end{array}$ \\
\hline \multirow{5}{*}{ BMI } & Underweight & $<18.5$ & $9(1.3)$ & & $9(1.3)$ \\
\hline & Normal & $18.5 \sim 24.9$ & $294(44.7)$ & & $294(44.7)$ \\
\hline & Obese class 1 & $25 \sim 29.9$ & $15(2.3)$ & $300(45.6)$ & $315(47.9)$ \\
\hline & Obese class 2 & $\geq 30.0$ & & $40(6.1)$ & $40(6.1)$ \\
\hline & \multicolumn{2}{|c|}{ Total } & $318(48.3)$ & $340(51.7)$ & $658(100.0)$ \\
\hline \multirow{3}{*}{ Rohrer } & Normal & $<1.6$ & $218(33.1)$ & & $218(33.1)$ \\
\hline & Obesity & $\geq 1.6$ & $100(15.2)$ & $340(51.7)$ & $440(66.9)$ \\
\hline & \multicolumn{2}{|c|}{ Total } & $318(48.3)$ & $340(51.7)$ & $658(100.0)$ \\
\hline \multirow{3}{*}{ WHR } & Normal & $<0.85$ & $69(10.5)$ & & $69(10.5)$ \\
\hline & Obesity & $\geq 0.85$ & $249(37.8)$ & $340(51.7)$ & $589(89.5)$ \\
\hline & \multicolumn{2}{|c|}{ Total } & $318(48.3)$ & $340(51.7)$ & $658(100.0)$ \\
\hline
\end{tabular}

2) Obesity analysis of body proportion

비만의 정도를 drop과 편평률 비교를 통해 60대 와 70 대 체형의 차이점을 독립표본 $\mathrm{T}$ 검정을 통해 분석한다.

\section{3) Classification of obesity body-types}

비만과 상관이 높은 변수를 찾아 대표항목으로 선 정하고, 모든 항목을 지수화하여 체형적 특성이 좀 더 명확해지는 분류방법을 사용하였다. 즉, 지수화한 치 수로 비만체형 요인을 도출하고, 군집분석을 통해 비 만체형을 선정하며, 분산분석, 교차분석을 실시하여 비만체형의 특징 및 연령대별 분포를 제시하였다. 또 한 분류된 비만체형의 형상화는 $3 \mathrm{D}$ 어패럴 $\mathrm{CAD}$ 프로그 램인 (주)클러버추얼패션의 CLO 3D(Marvelous Designer) v.4.30 프로그램을 이용해 구현하여 제시하였다.

\section{Results and Discussion}

1. Body measurement analysis of old-aged obese women

노년 비만여성의 연령에 따른 체형 변화를 고찰 하고자 연령을 60 69세의 60대와, 70 79세의 70대 집단으로 분류하고, 독립표본 $T$ 검정을 실시하여 집 단간의 유의차를 검증하였다. 또한 노년여성 중 정 상체형에 속하는 집단의 측정치를 제시하여 비만체 형과 비교하였다(Table 3).
이를 살펴보면 키의 경우, $p<.001$ 수준에서 연령 별로 유의한 차를 나타내 연령이 증가할수록 키가 작아지는 것을 알 수 있다. 둘레항목은 허리둘레, 배 꼽수준허리둘레 항목은 60 대에 비해 70 대로 갈수록 커지는 것으로 나타났으나, 하체에 해당하는 넙다리 둘레, 장딴지둘레는 연령이 높을수록 가늘어지는 것 으로 나타났다. 너비항목의 경우, 상체에 해당하는 가슴너비, 젖가슴너비의 경우 60 대와 70 대가 유의 한 차이를 나타내 60 대가 좀 더 상체가 비만한 것으 로 나타났다. 반면에 두께항목의 경우에는 겨드랑두 께는 60 대가 더 두꺼운 것으로 나타났으나, 엉덩이 두께를 제외하고 가슴두께, 젖가슴두께, 허리두께, 배꼽수준허리두께는 70 대로 갈수록 더 두꺼워지는 것으로 나타났다. 또한 길이항목의 경우, 앞중심길 이와 겨드랑뒤벽사이길이(뒤품)가 $p<.001$ 수준에서 집단 별로 유의한 차를 나타냈는데, 60 대가 큰 것으 로 나타나 상체가 좀 더 비만한 것으로 생각된다. 즉, 노년 비만체형에서도 연령에 따라 체형 변화를 보이는데, 키는 연령이 증가할수록 작아지는 것으로 나타났고, 다른 항목에 비해 특히 허리둘레, 배꼽수 준허리둘레가 연령이 높을수록 크게 증가되나, 다리 같은 하체부분은 연령이 증가함에 따라 감소하는 것으로 나타나, 노년의 특징이 비만체형에도 적용됨 을 알 수 있다. 또한 체간부의 두께항목이 연령이 높 을수록 두꺼워지는 것으로 나타나, 이는 선행연구 (Kim, Lee, Kim, \& Lee, 2012; Seong \& Ha, 2012)와 
〈Table 3〉 Comparison of body measurements by age group

(Unit: $\mathrm{cm})$

\begin{tabular}{|c|c|c|c|c|c|c|c|c|}
\hline & \multirow[t]{2}{*}{ Measurement } & \multicolumn{2}{|c|}{$\begin{array}{l}\text { Normal body types } \\
\qquad(\mathrm{n}=318)\end{array}$} & \multicolumn{2}{|c|}{$\begin{array}{c}60 \text { age Obese body } \\
\text { types }(n=195)\end{array}$} & \multicolumn{2}{|c|}{$\begin{array}{l}70 \text { age Obese body } \\
\text { types }(n=145)\end{array}$} & \multirow[t]{2}{*}{$t$-value } \\
\hline & & Mean & S.D. & Mean & S.D. & Mean & S.D. & \\
\hline \multirow{6}{*}{ Height } & Stature & 151.00 & 5.97 & 151.50 & 4.12 & 149.78 & 4.68 & $3.52^{* * *}$ \\
\hline & Cervical height & 128.71 & 5.34 & 129.09 & 3.93 & 128.23 & 4.59 & 1.80 \\
\hline & Acromion height & 121.80 & 5.25 & 122.35 & 3.97 & 121.19 & 4.60 & $2.43^{*}$ \\
\hline & Waist height(omphalion) & 87.33 & 4.36 & 85.64 & 3.55 & 84.80 & 4.42 & 1.90 \\
\hline & Hip height & 73.67 & 3.58 & 72.81 & 3.18 & 73.56 & 3.47 & $-2.07^{*}$ \\
\hline & Crotch height & 67.45 & 3.36 & 66.20 & 2.92 & 66.09 & 3.38 & 0.31 \\
\hline \multirow{11}{*}{$\begin{array}{l}\text { Circum- } \\
\text { ference }\end{array}$} & Neck base circumference & 37.03 & 2.13 & 39.10 & 2.25 & 39.04 & 2.19 & 0.24 \\
\hline & Chest circumference & 85.37 & 4.30 & 92.91 & 4.27 & 91.76 & 4.94 & $2.30^{*}$ \\
\hline & Bust circumference & 88.44 & 5.31 & 98.22 & 5.29 & 97.63 & 5.73 & 0.99 \\
\hline & Waist circumference & 80.17 & 6.60 & 90.52 & 6.22 & 92.88 & 6.53 & $-3.38^{* * *}$ \\
\hline & Waist C.(omphalion) & 86.00 & 6.96 & 95.80 & 6.19 & 99.00 & 5.79 & $-4.84^{* * *}$ \\
\hline & Hip circumference & 89.15 & 4.45 & 94.84 & 4.26 & 94.91 & 4.87 & -0.13 \\
\hline & Thigh circumference & 49.66 & 4.23 & 54.52 & 3.19 & 52.56 & 4.01 & $4.86^{* * *}$ \\
\hline & Knee circumference & 33.28 & 2.11 & 35.34 & 2.15 & 35.72 & 2.35 & -1.55 \\
\hline & Calf circumference & 31.00 & 2.30 & 34.19 & 2.14 & 33.11 & 2.13 & $4.63^{* * *}$ \\
\hline & Upper arm circumference & 27.00 & 2.32 & 30.17 & 2.26 & 29.75 & 2.54 & 1.59 \\
\hline & Wrist circumference & 15.58 & 0.83 & 16.20 & 0.80 & 16.27 & 0.91 & -0.79 \\
\hline \multirow{5}{*}{ Breadth } & Chest breadth & 27.50 & 1.81 & 29.39 & 1.90 & 28.75 & 1.72 & $3.22^{* *}$ \\
\hline & Bust breadth & 27.89 & 1.79 & 30.83 & 1.77 & 30.21 & 1.88 & $3.14^{* *}$ \\
\hline & Waist breadth & 26.77 & 2.03 & 29.83 & 2.10 & 30.26 & 2.24 & -1.83 \\
\hline & Waist breadth(omphalion) & 29.71 & 2.05 & 32.57 & 1.92 & 33.11 & 1.97 & $-2.52^{*}$ \\
\hline & Hip breadth & 31.96 & 1.43 & 32.96 & 1.39 & 33.05 & 1.54 & -0.56 \\
\hline \multirow{6}{*}{ Depth } & Armscye depth & 9.44 & 1.07 & 10.83 & 1.20 & 10.36 & 1.26 & $3.49^{* * *}$ \\
\hline & Chest depth & 20.18 & 1.53 & 22.06 & 1.60 & 22.55 & 1.94 & $-2.58^{*}$ \\
\hline & Bust depth & 23.75 & 1.82 & 26.51 & 1.90 & 27.29 & 2.08 & $-3.59^{* * *}$ \\
\hline & Waist depth & 22.21 & 2.23 & 25.84 & 2.07 & 26.70 & 2.23 & $-3.68^{* * *}$ \\
\hline & Waist depth(omphalion) & 22.62 & 2.38 & 26.06 & 2.12 & 27.37 & 2.21 & $-5.53^{* * *}$ \\
\hline & Hip depth & 21.32 & 2.06 & 24.37 & 2.12 & 24.37 & 2.47 & 0.00 \\
\hline \multirow{8}{*}{ Length } & Waist front length & 31.96 & 2.93 & 34.22 & 2.49 & 33.18 & 3.08 & $3.46^{* * *}$ \\
\hline & Interscye, front & 32.04 & 2.21 & 33.26 & 1.94 & 33.39 & 2.13 & -0.59 \\
\hline & Neck point to breast point & 28.48 & 2.18 & 29.76 & 2.33 & 30.40 & 2.28 & $-2.52^{*}$ \\
\hline & Scye depth & 17.69 & 1.76 & 17.81 & 1.76 & 17.97 & 1.75 & -0.82 \\
\hline & Waist back length & 38.24 & 2.88 & 39.36 & 2.67 & 39.18 & 3.32 & 0.53 \\
\hline & Biacromion length & 37.43 & 2.68 & 39.19 & 2.15 & 38.51 & 2.51 & $2.72 * *$ \\
\hline & Back interscye, length & 35.14 & 2.57 & 37.08 & 2.21 & 36.12 & 2.50 & $3.74^{* * *}$ \\
\hline & Arm length & 52.77 & 2.13 & 52.75 & 2.12 & 52.93 & 2.16 & -0.78 \\
\hline Other & Weight(kg) & 52.08 & 6.33 & 63.20 & 5.57 & 61.81 & 6.60 & $2.11^{*}$ \\
\hline
\end{tabular}

${ }^{*} p<.05, * * p<.01, * * * p<.001$ 
도 같은 결과임을 알 수 있다. 즉, 노년 비만여성은 성별과 관계없이 노인화되어가는 특성이 적용되어 허리, 배 부위는 증가하고, 키는 작아지며, 하체는 가늘어지고, 체간부의 두께는 두꺼워지는 특성을 나 타내었다. 이러한 신체적 특징은 패턴 설계 시 반드 시 고려되어야 할 부분으로 특히 증가한 배둘레와 엉덩이둘레의 비례, 배둘레와 가늘어지는 허벅지둘 레의 비례를 고려한 패턴 및 그레이딩룰의 개선이 필요하다. 또한 체간부 두께의 증가로 인한 진동두 께, 샅폭, 배두께 부위도 패턴 및 그레이딩룰의 조정 이 필요한 위치라 할 수 있다.

\section{Obesity analysis of body proportion}

노년 비만여성의 형태상 특징을 파악하고자 측정 치를 지수값으로 변환시켜 비만도, 신체비, drop, 편 평지수에 대한 연령대별 신체특성을 파악하였고, 정 상체형에 속하는 집단의 측정치를 제시하여 비만체 형과 비교하였다(Table 4).

비만 정도를 살펴보기 위해 Rohrer, BMI, WHR 지수로 비교한 결과, Rohrer, $\mathrm{BMI}$ 는 집단간의 유의 한 차이를 보이지는 않았으나, 복부지방율(WHR)에 서는 유의한 차이를 나타내 연령이 증가할수록 복 부비만도가 큰 것으로 나타났다. drop 차이에 의한 비교를 살펴보면 젖가슴둘레-엉덩이둘레 항목을 제 외한 모든 항목에서 유의한 차이를 보이고 있는데, 60 대보다 70 대의 drop 차가 적은 것으로 나타나, 연

$\langle$ Table 4〉 obesity analysis according to the index values

\begin{tabular}{|c|c|c|c|c|c|c|c|c|}
\hline & \multirow[t]{2}{*}{ Division } & \multicolumn{2}{|c|}{$\begin{array}{c}\text { Normal body } \\
\text { types } \\
(n=318)\end{array}$} & \multicolumn{2}{|c|}{$\begin{array}{c}60 \text { age obese } \\
\text { body types } \\
(n=195)\end{array}$} & \multicolumn{2}{|c|}{$\begin{array}{c}70 \text { age obese } \\
\text { body types } \\
(n=145)\end{array}$} & \multirow[t]{2}{*}{$t$-value } \\
\hline & & Mean & S.D. & Mean & S.D. & Mean & S.D. & \\
\hline \multirow{3}{*}{ Obesity rate } & BMI & 22.79 & 1.98 & 27.53 & 2.01 & 27.50 & 2.12 & 0.1 \\
\hline & Rohrer & 1.51 & 0.14 & 1.82 & 0.15 & 1.84 & 0.14 & -1.18 \\
\hline & WHR & 0.90 & 0.06 & 0.95 & 0.05 & 0.98 & 0.06 & $-3.99 * * *$ \\
\hline \multirow{5}{*}{$\begin{array}{c}\text { Drop } \\
\text { difference }\end{array}$} & Bust C.-Waist C. & 82.75 & 42.64 & 77.01 & 38.43 & 47.48 & 43.42 & $6.63 * * *$ \\
\hline & Hip C.-Waist C. & 89.81 & 56.58 & 43.19 & 51.14 & 20.29 & 56.83 & $3.89 * * *$ \\
\hline & Bust C.-Hip C. & -7.06 & 46.67 & 33.82 & 50.15 & 27.19 & 46.59 & 1.24 \\
\hline & Hip C.-Waist C(omphalion) & 31.47 & 55.98 & -9.57 & 49.10 & -40.91 & 43.15 & $6.24 * * *$ \\
\hline & Waist C.(omphalion)-Waist C. & 58.34 & 32.87 & 52.76 & 30.73 & 61.20 & 43.96 & $-1.98 *$ \\
\hline \multirow{5}{*}{$\begin{array}{c}\text { Body } \\
\text { proportion } \\
\text { divided by } \\
\text { breadth }\end{array}$} & Chest depth/Chest breadth & 0.74 & 0.06 & 0.75 & 0.07 & 0.79 & 0.07 & $-4.48 * * *$ \\
\hline & Bust depth/Bust breadth & 0.85 & 0.06 & 0.86 & 0.05 & 0.90 & 0.06 & $-7.19 * * *$ \\
\hline & Waist depth/Waist breadth & 0.83 & 0.06 & 0.87 & 0.05 & 0.88 & 0.06 & $-2.7 * *$ \\
\hline & Waist depth(omphalion)/Waist breadth(omphalion) & 0.76 & 0.06 & 0.80 & 0.05 & 0.83 & 0.06 & $-4.43 * * *$ \\
\hline & Hip width/Hip breadth & 0.67 & 0.06 & 0.74 & 0.06 & 0.74 & 0.07 & 0.32 \\
\hline \multirow{5}{*}{$\begin{array}{c}\text { Body } \\
\text { proportion } \\
\text { divided by } \\
\text { stature }\end{array}$} & Cervical height/Stature & 0.85 & 0.01 & 0.85 & 0.01 & 0.86 & 0.01 & $-4.25 * * *$ \\
\hline & Acromion height/Stature & 0.81 & 0.01 & 0.81 & 0.01 & 0.81 & 0.01 & -1.29 \\
\hline & Hip height/Stature & 0.49 & 0.02 & 0.48 & 0.01 & 0.49 & 0.02 & $-5.93 * * *$ \\
\hline & Waist H.(Omphalion)/Stature & 0.58 & 0.02 & 0.57 & 0.02 & 0.57 & 0.02 & -0.39 \\
\hline & Crotch height/Stature & 0.45 & 0.01 & 0.44 & 0.01 & 0.44 & 0.04 & -0.39 \\
\hline
\end{tabular}

Rohrer $=$ Weight $/$ Stature $(\mathrm{cm})^{3} \times 10^{5}$

$\mathrm{BMI}=$ Weight $/$ Stature $(\mathrm{m})^{2}$

WHR $=$ Waist rcumference - Hip circumference

${ }^{*} p<.05, * * p<.01, * * * p<.001$ 
령이 증가함에 따라 허리, 배부위가 더욱 증가됨을 알 수 있다. 편평지수에 의한 비교에서도 엉덩이 부 분을 제외한 모든 항목 간에 유의한 차이를 보이고 있는데, 연령이 증가할수록 체간부 두께가 두꺼워짐 을 알 수 있다. 키에 대한 신체비는 목뒤높이/키, 엉 덩이높이/키 항목에서 유의한 차이가 있는 것으로 나타났는데, 이는 연령이 낮을수록 하반신 길이가 길어짐을 나타낸다. 따라서 지수치에 의한 비만도 분석에서도 노인 비만여성은 연령이 높을수록 허리, 배둘레가 증가하고, 체간부 두께가 굵어지는 특징을 보이고 있다.

\section{Classification of obesity body-types}

\section{1) Factor analysis}

비만체형의 형태적 특성을 비교하기 위해 모든 항목을 지수화하여 비례치를 산출하였다. 즉, 너비항 목은 젖가슴너비, 둘레항목은 허리둘레, 두께항목은

〈Table 5〉 The result of correlation analysis

\begin{tabular}{l|c|c|c}
\hline \multicolumn{1}{c|}{ Item } & $\begin{array}{c}\text { Bust } \\
\text { breadth }\end{array}$ & $\begin{array}{c}\text { Bust } \\
\text { depth }\end{array}$ & Waist C. \\
\hline Waist B.(omphalion) & .62 & .59 & .61 \\
\hline Waist breadth & .61 & .64 & .83 \\
\hline Chest breadth & .58 & .23 & .18 \\
\hline Hip breadth & .37 & .30 & .34 \\
\hline Waist depth & .57 & .77 & .79 \\
\hline Waist D.(omphalion) & .39 & .67 & .75 \\
\hline Chest depth & .41 & .65 & .55 \\
\hline Hip depth & .35 & .39 & .38 \\
\hline Armscye depth & .31 & .23 & .15 \\
\hline Waist C.(omphalion) & .39 & .69 & .83 \\
\hline Bust circumference & .61 & .71 & .75 \\
\hline Chest circumference & .59 & .63 & .67 \\
\hline Hip circumference & .44 & .50 & .55 \\
\hline Knee circumference & .29 & .35 & .44 \\
\hline Upper arm circumference & .49 & .39 & .40 \\
\hline Wrist circumference & .25 & .21 & .38 \\
\hline Calf circumference & .35 & .16 & .24 \\
\hline Thigh circumference & .34 & .19 & .22 \\
\hline
\end{tabular}

젖가슴두께가 각각 상관이 높은 항목으로 나타나, 이를 대표항목으로 정해 지수치로 변환하여 사용하 였다. 〈Table 5〉는 요인분석에 사용된 항목과 상관 관계를 분석한 것이다.

〈Table 6〉은 요인분석 결과를 나타낸 것으로 4 개 의 요인이 도출되었고, 총 설명량은 $68.71 \%$ 이다. 1 요인은 상반신과 하반신을 포함하는 전체적 둘레를 나타내는 요인이고, 2 요인은 체간부의 너비를 나타 내는 요인이다. 3 요인은 허리와 엉덩이를 포함한 복 부 두께를 나타내는 항목이고, 4 요인은 가슴과 겨드 랑이를 포함한 상체두께를 나타낸다.

\section{2) Cluster analysis}

요인분석 결과로 얻어진 4 개 요인들의 요인점수를 독립변수로 군집분석을 실시하여 비만체형의 특징이 뚜렷이 나타나는 3 개 유형으로 분류하였다. 〈Table $7\rangle,\langle$ Table 8 >은 군집분석에 의해 분류된 체형의 특 징을 알아보기 위해 요인점수와 지수치에 대한 분 산분석과 던컨테스트를 실시한 결과이다.

유형 1 은 둘레와 너비요인은 큰 편이고, 상체두께 요인은 가장 작고, 복부두께 요인은 중간에 속한다. 유형2는 둘레요인은 작고, 너비는 중간이며, 복부두 께 요인이 가장 작은 유형이다. 유형3은 둘레요인은 큰 편이고, 너비가 가장 작으며, 두께요인이 가장 큰 유형이다. 체형별 특성을 좀 더 자세히 살펴보기 위 해 지수치에 의한 유형별 특징을 살펴보면 유형 1 은 상의 둘레요인(가슴둘레/허리둘레, 젖가슴둘레/허리 둘레)은 중간에 속하고, 하의 둘레요인(배꼽수준허 리둘레/허리둘레, 엉덩이둘레/허리둘레, 넙다리둘레/ 허리둘레, 무릎둘레/허리둘레)은 가장 큰 값을 나타 내, 허리둘레에 비해 배둘레, 엉덩이둘레, 넙다리둘 레 등이 큰 체형이다. 너비항목에서도 특히 배꼽수 준허리너비/젓가슴너비항목이 가장 큰 것으로 나타 났고, 두께항목에서도 상체두께 항목은 작고 복부두 께 항목이 큰 것으로 나타나, 허리는 가늘고 복부가 발달된 하체비만 유형임을 알 수 있다. 유형2는 상의 둘레요인과 하의 둘레요인이 가장 낮게 나타났는데, 이는 허리둘레를 기준으로 한 비례치로 비교할 때 상대적으로 다른 항목이 낮은 것을 의미하므로, 특 히 허리둘레가 큰 비만 집단이라고 할 수 있다. 또한 허리너비/젖가슴너비, 배꼽수준허리너비/젖가슴너비, 
$\langle$ Table 6〉 The result of factor analysis

\begin{tabular}{|c|c|c|c|c|c|}
\hline Item & $\begin{array}{c}\text { Factor } 1 \\
\text { (Circumference) }\end{array}$ & $\begin{array}{l}\text { Factor } 2 \\
\text { (Breadth) }\end{array}$ & $\begin{array}{c}\text { Factor } 3 \\
\text { (Depth of } \\
\text { the abdomen) }\end{array}$ & $\begin{array}{c}\text { Factor } 4 \\
\text { (Depth of the } \\
\text { upper body) }\end{array}$ & $h^{2}$ \\
\hline Hip C./Waist C. & .89 & & & & 0.66 \\
\hline Thigh C./Waist C. & .85 & & & & 0.67 \\
\hline Calf C./Waist C. & .82 & & & & 0.68 \\
\hline Chest C./Waist C. & .82 & & & & 0.68 \\
\hline Knee C./Waist C. & .80 & & & & 0.68 \\
\hline Wrist C./Waist C. & .77 & & & & 0.7 \\
\hline Upper Arm C./Waist C. & .73 & & & & 0.69 \\
\hline Bust C./Waist C. & .73 & -.42 & & & 0.71 \\
\hline Neck base C./Waist C. & .70 & & & & 0.7 \\
\hline Waist C.(omphalion)/Waist C. & .54 & & .38 & -.60 & 0.69 \\
\hline Hip breadth/Bust breadth & & .86 & & & 0.68 \\
\hline Waist B.(omphalion)/Bust B. & & .83 & & & 0.71 \\
\hline Waist breadth/Bust breadth & -.55 & .66 & & & 0.75 \\
\hline Chest breadth/Bust breadth & .37 & .40 & & & 0.68 \\
\hline Waist D.(omphalion)/Bust D. & & & .92 & & 0.72 \\
\hline Waist depth/Bust depth & -.33 & & .77 & & 0.73 \\
\hline Hip depth/Bust depth & .33 & & .64 & & 0.68 \\
\hline Chest depth/Bust depth & & & .33 & .59 & 0.7 \\
\hline Armscye depth/Bust depth & .49 & & & .55 & 0.68 \\
\hline Eigen value & 6.97 & 2.4 & 2.29 & 1.39 & \\
\hline$\%$ of variance explained & 36.67 & 12.65 & 12.05 & 7.34 & \\
\hline Cummulative $\%$ of variance explained & 36.67 & 49.33 & 61.38 & 68.71 & \\
\hline
\end{tabular}

$\langle$ Table 7〉 Comparison of means according to factor score

\begin{tabular}{|c|c|c|c|c|}
\hline Factor & $\begin{array}{l}\text { Group } 1 \\
(n=95)\end{array}$ & $\begin{array}{l}\text { Group } 2 \\
(\mathrm{n}=126)\end{array}$ & $\begin{array}{l}\text { Group } 3 \\
(n=119)\end{array}$ & $F$-value \\
\hline $\begin{array}{c}\text { Factor } 1 \\
\text { (Circumference) }\end{array}$ & $.57 \mathrm{~B}$ & $-.78 \mathrm{~A}$ & $.37 \mathrm{~B}$ & $97.82 * * *$ \\
\hline $\begin{array}{l}\text { Factor } 2 \\
\text { (Breadth) }\end{array}$ & $.70 \mathrm{C}$ & $-.10 \mathrm{~B}$ & $-.46 \mathrm{~A}$ & $46.00 * * *$ \\
\hline $\begin{array}{c}\text { Factor } 3 \\
\text { (Depth of the abdomen) }\end{array}$ & $.19 \mathrm{~B}$ & $-.59 \mathrm{~A}$ & $.48 \mathrm{C}$ & $47.26 * * *$ \\
\hline $\begin{array}{c}\text { Factor } 4 \\
\text { (Depth of the upper body) }\end{array}$ & $-.83 \mathrm{~A}$ & $-.02 \mathrm{~B}$ & $.69 \mathrm{C}$ & $94.54 * * *$ \\
\hline
\end{tabular}

$*_{p}<.05, * * p<.01, * * * p<.001$

$\mathrm{C}>\mathrm{B}>\mathrm{A}$ : Letters indicate significant difference in groups by Duncan test. 
〈Table 8〉 Comparison of means according to item

\begin{tabular}{|c|c|c|c|c|c|}
\hline & Item & $\begin{array}{c}\text { Group } 1 \\
(\mathrm{n}=95)\end{array}$ & $\begin{array}{c}\text { Group } 2 \\
(n=126)\end{array}$ & $\begin{array}{l}\text { Group } 3 \\
(n=119)\end{array}$ & $F$-value \\
\hline & Neck base C./Waist C. & $0.44 \mathrm{~B}$ & $0.41 \mathrm{~A}$ & $0.43 \mathrm{~B}$ & $22.99 * * *$ \\
\hline & Chest C./Waist C. & $1.02 \mathrm{~B}$ & $0.98 \mathrm{~A}$ & $1.03 \mathrm{C}$ & $35.95 * * *$ \\
\hline & Bust C./Waist C. & $1.08 \mathrm{~B}$ & $1.05 \mathrm{~A}$ & $1.08 \mathrm{~B}$ & $15.46^{* * *}$ \\
\hline & Waist C.(omphalion)/Waist C. & $1.11 \mathrm{C}$ & $1.04 \mathrm{~A}$ & $1.06 \mathrm{~B}$ & $124.79 * * *$ \\
\hline$C^{*} \quad c_{-}$ & Hip C./Waist C. & $1.08 \mathrm{C}$ & $0.99 \mathrm{~A}$ & $1.05 \mathrm{~B}$ & $100.19 * * *$ \\
\hline 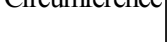 & Upper arm C./Waist C. & $0.34 \mathrm{~B}$ & $0.31 \mathrm{~A}$ & $0.34 \mathrm{~B}$ & $47.77 * * *$ \\
\hline & Wrist C./Waist C. & $0.18 \mathrm{~B}$ & $0.17 \mathrm{~A}$ & $0.18 \mathrm{~B}$ & $67.30 * * *$ \\
\hline & Thigh C./Waist C. & $0.61 \mathrm{~B}$ & $0.56 \mathrm{~A}$ & $0.60 \mathrm{~B}$ & $56.89 * * *$ \\
\hline & Knee C./Waist C. & $0.41 \mathrm{C}$ & $0.37 \mathrm{~A}$ & $0.39 \mathrm{~B}$ & $69.43 * * *$ \\
\hline & Calf C./Waist C. & $0.38 \mathrm{~B}$ & $0.35 \mathrm{~A}$ & $0.38 \mathrm{~B}$ & $62.50 * * *$ \\
\hline & Chest breadth/Bust breadth & $0.97 \mathrm{~B}$ & $0.94 \mathrm{~A}$ & $0.96 \mathrm{~B}$ & $12.52 * * *$ \\
\hline & Waist breadth/Bust breadth & $0.98 \mathrm{~B}$ & $1.01 \mathrm{C}$ & $0.96 \mathrm{~A}$ & $23.81 * * *$ \\
\hline Diéautil & Waist B.(omphalion)/Bust B. & $1.12 \mathrm{C}$ & $1.07 \mathrm{~B}$ & $1.05 \mathrm{~A}$ & $57.92 * * *$ \\
\hline & Hip breadth/Bust breadth & $1.13 \mathrm{~B}$ & $1.07 \mathrm{~A}$ & $1.06 \mathrm{~A}$ & $48.80 * * *$ \\
\hline & Waist depth/Bust depth & $0.96 \mathrm{~A}$ & $0.97 \mathrm{~A}$ & $1.00 \mathrm{~B}$ & $21.90 * * *$ \\
\hline Depth of the & Waist D.(omphalion)/Bust D. & $1.01 \mathrm{~B}$ & $0.97 \mathrm{~A}$ & $1.01 \mathrm{~B}$ & $19.06 * * *$ \\
\hline & Hip depth/Bust depth & $0.93 \mathrm{~B}$ & $0.85 \mathrm{~A}$ & $0.96 \mathrm{C}$ & $67.66^{* * *}$ \\
\hline Depth of the & Armscye depth/Bust depth & $0.39 \mathrm{~B}$ & $0.37 \mathrm{~A}$ & $0.43 \mathrm{C}$ & $71.23 * * *$ \\
\hline upper body & Chest depth/Bust depth & $0.81 \mathrm{~A}$ & $0.82 \mathrm{~A}$ & $0.86 \mathrm{~B}$ & $34.98 * * *$ \\
\hline
\end{tabular}

${ }^{*} p<.05, * * p<.01, * * * p<.001$

$\mathrm{C}>\mathrm{B}>\mathrm{A}$ : Letters indicate significant difference in groups by Duncan test.

엉덩이너비/젖가슴너비 등은 비례치가 1 에 가까워 체 간부가 일자인 체형이며, 복부가 특히 발달한 비만 유형이다. 유형3은 둘레요인은 중간에 속하고, 너비 는 작으며, 측면두께는 큰 값을 나타내어 전체적으로 비만한 형태로 균형 잡힌 전신비만 유형에 속한다.

군집분석을 통해 분류된 비만유형의 특징과 분포
도를 요약하면 〈Table 9〉와 같다. 유형1은 하체가 비만하고, 특히 배가 발달한 하체비만 체형으로 95 명 $(27.9 \%)$ 의 분포를 나타냈고, 유형2는 허리가 비만 해서 가슴부터 배까지 일자형태를 이루는 복부비만 체형으로 126 명(37.1\%)의 가장 많은 분포를 나타냈 다. 유형 3 은 상체와 하체가 균형 잡힌 전신비만 체형

〈Table 9〉 Characteristice of body-types

\begin{tabular}{c|l|c}
\hline Group & \multicolumn{1}{|c|}{ Characteristice } & Distribution(\%) \\
\hline $\begin{array}{c}\text { Group 1 } \\
\text { Lower-body obesity) }\end{array}$ & $\begin{array}{l}\text { - Lower body obesity with the more developed abdomen and hip than the upper } \\
\text { body. } \\
\text { - The abdominal girth is large with the narrow shoulder and slimmer waist }\end{array}$ & 95(27.9) \\
\hline $\begin{array}{c}\text { Group 2 } \\
\text { (Abdominal obesity) }\end{array}$ & $\begin{array}{l}\text { - There is a straight line from the chest to the abdomen due to the obese waist. } \\
\text { The upper body is more developed than the lower body. }\end{array}$ & $126(37.1)$ \\
\hline $\begin{array}{c}\text { Group 3 } \\
\text { (Whole-body obesity) }\end{array}$ & - There is overall balance in the obesity of whole body. & $119(35.0)$ \\
\hline
\end{tabular}


으로 119 명(35.0\%)이 분포하여 노년여성 비만체형 중 두 번째로 많은 체형이다.

\section{3) CLO 3D body shape}

분류된 3가지 비만체형의 신체치수를 CLO 3D (Marvelous Designer)를 이용해 구현한 노년 비만여 성의 인체형상 데이터이다(Fig. 1). 그러나 이를 살 펴보면 주로 정상 체형의 바디를 만드는데 필요한 항목인 높이, 둘레, 길이 항목의 데이터 값을 사용하 고 있어, 실제로 등이 굽은 형태나 젖혀진 형태 등의 측면 형태를 구현할 수 없어 실제 노인체형과 다름 을 알 수 있다. 따라서 본 연구의 체형분류 결과로 제시된 인체형상을 일반화하기에는 한계가 있다. 그 러나 의류제작을 위해 사용되는 바디는 측면이 정 상체형(바른체형)에 속하며, 둘레나 길이 등의 치수
를 달리하여 바디를 제작하여 사용하기 때문에, 상 반신이 비만이거나 하반신이 비만인 체형, 또는 전 체적 비만체형을 측면이 정상체형(바른체형) 바디 로 구현하여 패턴제작이나 피팅이 가능하도록 활용 할 수 있다고 생각된다. 〈Table 10〉은 인체영상 테 이터 구현에 사용된 비만체형의 신체측정 자료로, 계측치에 대한 분산분석과 던컨테스트 결과이다. 분 류된 체형은 목뒤높이, 허리높이, 겨드랑앞벽사이길 이(앞품), 어깨사이길이를 제외하고 유의한 차이를 나타내었으며, 둘레항목은 엉덩이둘레, 무릎둘레를 제외하고 유의한 차이를 나타내었다.

\section{4) Distribution of body-types by age}

분류된 3 개 비만체형의 유형과 연령층과의 관계 를 알아보기 위한 분할표 분석결과이다(Table 11).

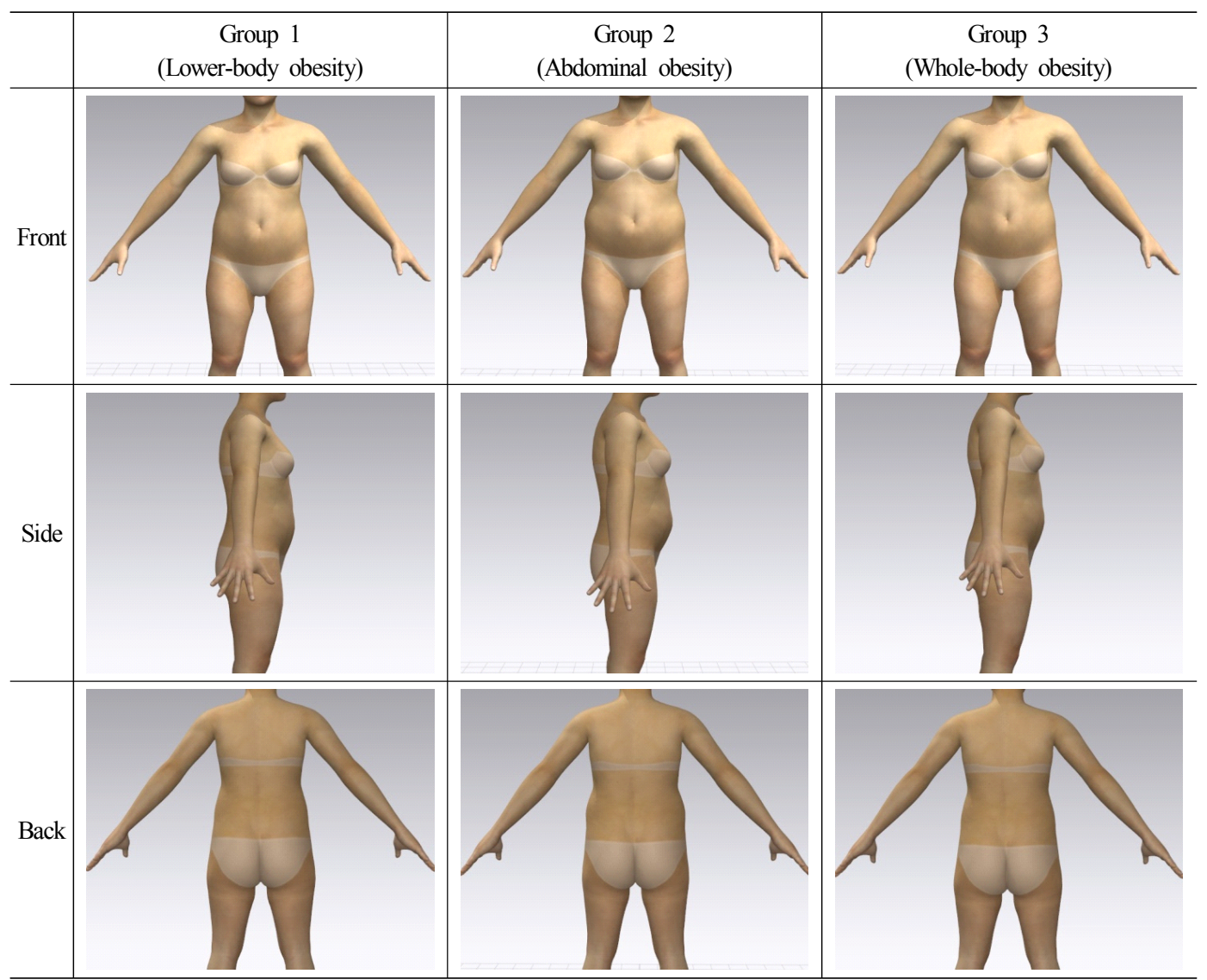

〈Fig. 1〉 Body types of old aged obese women 
$\langle$ Table 10〉 Comparison of means according to body measurements

\begin{tabular}{c|l|c|c|c|c}
\hline \multicolumn{2}{c|}{ Item } & $\begin{array}{c}\text { Group 1 } \\
(\mathrm{n}=95)\end{array}$ & $\begin{array}{c}\text { Group 2 } \\
(\mathrm{n}=126)\end{array}$ & $\begin{array}{c}\text { Group 3 } \\
(\mathrm{n}=119)\end{array}$ & $F$-value \\
\hline \multirow{5}{*}{ Height } & Cervical height & 128.31 & 129.11 & 128.64 & 1.00 \\
\cline { 2 - 6 } & Waist height & 92.32 & 92.24 & 92.21 & 0.01 \\
\cline { 2 - 6 } & Hip height & $72.83 \mathrm{~B}$ & $73.90 \mathrm{C}$ & $72.57 \mathrm{~B}$ & $5.64^{* *}$ \\
\hline \multirow{5}{*}{ Circumference } & Bust circumference & $95.54 \mathrm{~A}$ & $100.58 \mathrm{C}$ & $97.15 \mathrm{~B}$ & $29.17^{* * *}$ \\
\cline { 2 - 6 } & Waist circumference & $88.28 \mathrm{~A}$ & $95.62 \mathrm{C}$ & $89.78 \mathrm{~B}$ & $55.15^{* * *}$ \\
\cline { 2 - 6 } & Waist C.(omphalion) & $97.54 \mathrm{~B}$ & $99.06 \mathrm{~B}$ & $94.86 \mathrm{~A}$ & $15.45^{* * *}$ \\
\cline { 2 - 6 } & Hip circumference & 95.45 & 94.77 & 94.52 & 1.17 \\
\cline { 2 - 6 } & Thigh circumference & $54.06 \mathrm{C}$ & $53.02 \mathrm{~B}$ & $54.10 \mathrm{C}$ & $3.35^{*}$ \\
\cline { 2 - 6 } & Knee circumference & 35.82 & 35.37 & 35.39 & 1.32 \\
\cline { 2 - 6 } & Calf circumference & $33.42 \mathrm{~B}$ & $33.30 \mathrm{~B}$ & $34.43 \mathrm{C}$ & $9.85^{* * *}$ \\
\cline { 2 - 6 } & Upper arm circumference & $29.56 \mathrm{~B}$ & $29.81 \mathrm{~B}$ & $30.52 \mathrm{C}$ & $4.95^{* *}$ \\
\cline { 2 - 6 } & Wrist circumference & $16.09 \mathrm{~B}$ & $16.13 \mathrm{~B}$ & $16.45 \mathrm{C}$ & $6.22^{* *}$ \\
\hline & Interscye, front & $32.95 \mathrm{~A}$ & $33.33 \mathrm{AB}$ & $33.59 \mathrm{~B}$ & 2.70 \\
\cline { 2 - 6 } & Back interscye, length & $36.02 \mathrm{~B}$ & $37.03 \mathrm{C}$ & $36.81 \mathrm{C}$ & $5.29^{* *}$ \\
\cline { 2 - 6 } & Waist back length & $37.97 \mathrm{~A}$ & $40.32 \mathrm{C}$ & $39.23 \mathrm{~B}$ & $18.78^{* * *}$ \\
\cline { 2 - 6 } & Biacromion length & 38.76 & 38.86 & 39.06 & 5.49 \\
\cline { 2 - 6 } & Arm length & $52.45 \mathrm{~B}$ & $53.32 \mathrm{C}$ & $52.60 \mathrm{~B}$ & $5.65^{* *}$ \\
\hline
\end{tabular}

$*_{p}<.05, * * p<.01, * * * p<.001$

$\mathrm{C}>\mathrm{B}>\mathrm{A}$ : Letters indicate significant difference in groups by Duncan test.

〈Table 11〉 Crosstabs of body-types \& age

\begin{tabular}{c|c|c|c}
\hline Body types & $60-69$ Age & $70 \sim 79$ Age & Total(\%) \\
\hline Group 1(Lower-body obesity) & $42(21.0)$ & $53(36.6)$ & $95(27.9)$ \\
\hline Group 2(Abdominal obesity) & $61(31.3)$ & $65(44.8)$ & $126(37.1)$ \\
\hline Group 3(Whole-body obesity) & $92(47.2)$ & $27(18.6)$ & $119(35.0)$ \\
\hline Total(\%) & $195(57.3)$ & $145(42.7)$ & $340(100.0)$ \\
\hline \multicolumn{2}{|c|}{$X^{2}=30.205^{* * *}$} \\
\end{tabular}

( ) percentage in same group

$\mathrm{X}^{2}$ 검증결과, 체형과 연령대 사이에 유의한 차이를 나타내고 있는데, 유형내의 분포를 살펴보면 60대 는 전신비만 체형이 가장 많은 것으로 나타났는데, 60 대는 복부비만 체형과 전신비만 체형이 주류를 이루다가 70 대는 하체비만 체형과 복부비만 체형이 더 많이 늘어나고, 전신비만 체형은 줄어드는 것으 로 나타났다. 이는 노년으로 갈수록 복부의 지방침 착으로 복부비만 체형이 많아진다고 한 선행 연구
(Yoon, Yoon, \& An, 2013)의 결과와 같은 것으로 70 대에는 복부가 더욱 비만해져 복부비만 체형이 증 가됨을 알 수 있다.

\section{Conclusion}

본 연구는 실버 의류산업 활성화의 일환으로 증가 추세에 있는 60 79세의 노년 여성 중에 Rohrer 지수 
1.6 이상, 체질량지수(BMI) 25 이상, 복부지방율(WHR) 0.85 이상을 만족시키는 비만여성 340 명을 연구대상 으로 하여 비만집단의 신체적 특징을 분석하고, 체형 유형화를 통해 비만여성의 체형별 특징을 파악하여, 체형 특성이 반영된 패턴 제작이 가능하도록 의복설 계의 기초자료를 제공하는 데에 목적이 있다.

연구결과를 요약하면 다음과 같다.

첫째, 노년 비만여성의 연령에 따른 신체적 특징 은 키는 연령이 증가할수록 작아지며, 특히 허리둘 레, 배꼽수준허리둘레가 연령이 높을수록 크게 증가 되며, 다리와 같은 하체부분은 연령이 증가함에 따라 감소하는 것으로 나타났다. 반면, 체간부의 두께항목 은 연령이 증가할수록 두꺼워지는 것으로 나타나, 노년 비만여성은 성별과 관계없이 노인화되어가는 특성이 나타남을 알 수 있다. 따라서 패턴설계 시 증 가하는 배둘레와 엉덩이둘레의 비례, 배둘레와 가늘 어지는 허벅지둘레의 비례를 고려한 설계가 필요하 며, 체간부 두께의 증가로 인한 진동두께, 샅폭, 배두 께 부위도 패턴 및 그레이딩룰의 조정 시, 일반패턴 과 다른 포인트값 조정이 필요한 위치라 할 수 있다.

둘째, 연령대별 비만 정도를 비교한 결과, Rohrer, $\mathrm{BMI}$ 는 연령대별 차이를 보이지는 않았으나, 복부지 방율(Waist-Hip Ratio: WHR)에서는 유의한 차이를 나타내, 연령이 증가할수록 복부비만도가 큰 것으로 나타났다. Drop 치에 대한 비교에서도 60 대보다 70 대의 drop 차가 적은 것으로 나타나, 가슴, 엉덩이를 제외하고 연령이 높을수록 허리, 배부위가 더욱 증 가됨을 알 수 있고, 편평지수에 의한 비교에서도 연 령이 증가할수록 체간부 두께가 두꺼워지는 것으로 나타났다. 따라서 고령의 비만여성에 대한 비만도 분석에서도 연령이 높을수록 허리, 배둘레 부위가 증가하고, 체간부 두께도 두꺼워지는 신체적 특징이 나타남을 알 수 있다.

셋째, 비만체형의 형태적 특성을 비교하기 위해 모든 항목을 지수화하여 비례치를 산출하여 요인분 석을 실시한 결과는 4 개의 요인이 도출되었고, 둘레 요인과 너비 요인, 복부 두께를 나타내는 요인, 상체 두께를 나타내는 요인으로 분류되었다. 군집분석을 통해 분류된 비만유형은 3 가지 형태로 유형 1 은 배 가 발달한 하체비만 체형이고, 유형 2 는 허리가 비만 해서 가슴부터 배까지 일자형태를 이루는 비만형으
로 상체가 발달한 복부비만 체형이다. 유형 3 은 전체 가 비만하지만 균형 잡힌 비만형으로 전신비만 체 형이다. 연령대별 비만 유형의 변화를 살펴본 결과, 60 대는 복부비만 체형과 전신비만 체형이 주로 많 이 분포하나, 70 대에서는 전신비만 체형은 줄고, 복 부의 지방침착에 의한 복부비만 체형과 하체비만 체형이 많아지는 것으로 나타났다.

또한 분류된 유형을 CLO 3D(Marvelous Designer) 를 이용해 구현한 인체형상 데이터는 측면 형태를 구현할 수 없어 실제 노인체형을 구현하기에는 한 계가 있으나, 정상체형(바른체형)에 비만 정도나 비 만 위치를 구현할 수는 있어 의류제작을 위해 사용 되는 비만체형의 바디를 형상화할 수 있었다는 점 에서 의미가 있다고 생각된다.

본 연구는 체형을 좀 더 형태적으로 분류하고자 측정치를 지수화하여 분석하였으나, 직접측정치를 적용해서 분석한 연구와 다소 차이가 있어 이를 확 대 해석하기에는 한계가 있다. 따라서 후속 체형연 구에서는 두 가지 분류방법를 비교하여 형태적 특 성을 잘 설명할 수 있는 연구방법을 제시하는 연구 가 필요할 것으로 생각된다. 그러나 본 연구 결과는 60 대 이상 79 세까지 확대하여 노년여성의 비만체형 에 대한 정보를 제공한 것으로 신체 특징을 패턴에 적용하여 신체적합성이 높은 의복을 생산하는데 도 움이 되고, 착용 만족도를 증가시킬 수 있는 기성복 개발에 도움이 되는 자료로 활용될 수 있을 것이다.

\section{References}

Choi, H. S., \& Lee, J. H. (1995). Characterizing for age group of obese women's body shape for clothing design. Journal of the Korean Society of Clothing and Textiles, 19(5), 842-852.

Choi, Y. L., Han, S. A., \& Nam, Y. J. (2009). An exploratory study on the proportion of the male body according to obesity. Journal of the Korean Society of Clothing and Textiles, 33(8), 13061314.

Ha, H. J. (2002). A study on the apparel sizing system based on physical characteristics of plus-size women, by age. Unpublished doctoral dissertation, 
Sungkyunkwan University, Seoul, Korea.

Kim, H. S., \& Lee, M. H. (2008). A study on the body types of 40s, 50s, 60s of obese women. Journal of the Korean Society of Clothing and Textiles, 32(4), 618-629. doi:10.5850/JKSCT.2008. 32.4 .618

Kim, H. S., Lee, S. Y., Kim, J. M., \& Lee, J. H. (2012). Lower somatotype analysis of middle and older aged women: Focused on women in 40s to 60 s. Journal of the Korean Society of Costume, 62(3), 84-95. doi:10.7233/jksc.2012.62.3.084

Kim, J. S. (2010). Development of health status scale for abdominal obesity elderly. Journal of the Korean Gerontological Society, 30(4), 1095-1106.

Kim, S. A., \& Choi, H. S. (2006). An analysis of body shapes in aged abdominal obese women for apparel pattern design. Journal of the Korean Society of Clothing and Textiles, 30(12), 1690-1696.

Korea Health Industry Development Institute. (2006, December). Study on development of strategy for prevention and management of obesity. Retrieved March 7, 2015, from http://www.khidi.or.kr/board/ view?linkId=100368\&menuId=MENU00085

Korean Agency for Technology and Standards. (2004). The fifth human body measurement report (Size Korea). Gwacheon: Ministry of Knowledge Economy.

Korean Agency for Technology and Standards. (2006, November 17). 2006 report of the academic research service for the body measurements of Korean people. Retrieved March 7, 2015, from http:// sizekorea.kats.go.kr

Korean Society for the Study of Obesity. (2012, October). 비만치료 지침 2012 [Obesity treatmentguidelines 2012]. Retrieved March 21, 2015, from http:// www.kosso.or.kr/general/

Lee, H. J., Kim, J. Y., \& Kim, J. (2006). A study on lower body somatotype for briefs design development of the elderly women (Part 2): Focused on the women in the 60s and 70s in Jeonbuk. The Research Journal of the Costume Culture, 14(1), 79-92.
Lee, J. H. (1996). A study on classification of body shape and apparel sizing system for obese women. Unpublished doctoral dissertation, Ewha Womans University, Seoul, Korea.

Lee, J. H. (2002). Fit of ready-to-wear apparel for adult women by somatotype. Family and Environment Research, 40(12), 189-197.

Lee, J. Y., \& Joo, S. Y. (2005). Size analysis of readymade clothing for elderly women and fit evaluation according to their body type. Journal of the Korean Society of Clothing and Textiles, 29(8), 1092-1101.

Lee, S. S. (2009). A study on self-esteem and physical satisfaction of the elderly women. Journal of the Korean Gerontological Society, 29(2), 547-562.

Minstry of Health \& Welfare. (2009, December 8). 2008 년도 국민건강영양조사 결과 발표 [2008 National Health and Nutrition Examination Survey results released]. Retrieved March 10, 2015, from http:// www.mw.go.kr/front_new/al/sal0301vw.jsp?PAR _MENU_ID $=04 \&$ MENU_ID $=0403 \&$ page $=307 \&$ CONT_SEQ $=224021$

Seok, H. J., \& Kim, I. S. (2003). A study on the fit preference tendency for ready-to-wear by the age and obesity level of adult women. Family and Environment Research, 41(9), 17-29.

Seong, O. J., \& Ha, H. J. (2012). A study of middle aged obese men's body shapes: 35 55 years of age. Journal of Korea Design Forum, 35(0), 39-50.

Statistics Korea. (2011, September 29). Elderly statistics. Retrieved January 29, 2015, from http://sgis. kostat.go.kr/publicsmodel/

Yoon, H. J., \& Choi, H. S. (2009). Upper body shape classification and the characteristics of obese women. Journal of the Korean Society of Clothing and Textiles, 33(8), 1262-1272.

Yoon, J. W., Yoon, H. J., \& An, J. S. (2013). An analysis of upper-body shapes in obese women for apparel pattern design. Fashion \& Textile Research Journal, 15(1), 130-137. doi:10.5805/ SFTI.2013.15.1.130 